\title{
The Effect of Phenyramidol on Neural Development in Early Chicken Embryo Model
}

\author{
Onur OZGURAL ${ }^{1}$, Burak BAHADIR ${ }^{1}$, Ihsan DOGAN¹, Umit EROGLU ${ }^{1}$, Serhat AKTAN¹, Irem KAR², Gizem CAKICl ${ }^{3}$,
} Eyyub S M AL-BEYATI', Gokmen KAHILOGULLARI', Agahan UNLU'

\author{
${ }^{1}$ Ankara University, School of Medicine, Department of Neurosurgery, Ankara, Turkey \\ ${ }^{2}$ Ankara University, School of Medicine, Department of Biostatistics, Ankara, Turkey \\ ${ }^{3}$ Ege University, School of Medicine, Department of Pediatrics, Izmir, Turkey
}

Corresponding author: Onur OZGURAL onurozgural@yahoo.com

\section{ABSTRACT}

AIM: To investigate the effects of Phenyramidol (Phe) on neural development in an early chicken embryo model.

MATERIAL and METHODS: Sixty fertile non-pathogenic Super Nick eggs were incubated for 24 hours (h) and divided into four groups of 15 eggs each. Phe was administrated through the sub-blastoderm, and the eggs were incubated for another $24 \mathrm{~h}$. All eggs were opened after $48 \mathrm{~h}$ of incubation, and the embryos were evaluated morphologically and histopathologically.

RESULTS: In Group 1 (control group), none exhibited neural tube defects (NTDs) (0\%), 1 (6.6\%) was undeveloped; in Group 2 (low dosages), 1 did not develop (6.6\%); in Group 3 (normal dosages), 2 (13.4\%) had NTDs, 1 (6.6\%) was undeveloped; in Group 4 (high dosages), 5 (33.3\%) had NTDs, 2 (13.3\%) were undeveloped.

CONCLUSION: In light of the results, it was determined that the use of increasing doses of Phe led to defects in midline closure in early chicken embryos. This is the first report in the literature on Phe used in an early chicken embryo model.

KEYWORDS: Neural tube defect, Growth retardation, Myorelaxant drug, Phenyramidol, Undeveloped embryo, Chicken embryo

ABBREVIATIONS: NTDs: Neural tube defects, Phe: Phenyramidol

\section{INTRODUCTION}

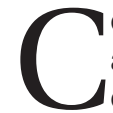

ongenital malformations are physical deformities that affect one or more organs. The worldwide incidence of central nervous system malformations is second only to that of cardiovascular congenital malformations. Neural tube defects (NTDs) constitute an important part of these congenital malformations $(14,19)$, with an incidence of approximately $6 / 10000$ pregnancies (26).

Pain that originates in the musculoskeletal system is a frequently encountered disorder that leads to loss of work, especially in industrialization countries; therefore, many drugs, such as simple analgesics, non-steroidal anti- inflammatory drugs, opioids and myorelaxants are often used to relieve the pain. Phenyramidol $\mathrm{HCl}\left[(\mathrm{Phe})\left(\mathrm{Cabral}{ }^{\circledR}\right.\right.$, Recordati llac, Tekirdag, Turkiye)] is a potent, non-narcotic central myorelaxant that affects the nervous system. The drug belongs to pregnancy category $\mathrm{C}$, which indicates that no studies have been conducted on the drug in humans (17). In our study, we determined the effects of Phe on the neural development in an early chick embryo model.

\section{MATERIAL and METHODS}

The study was conducted at Ankara University, in the Departments of Neurosurgery and Neuroembryology
Onur OZGURAL : (D) : 0000-0003-0592-6139 Burak BAHADIR (D) : 0000-0003-2456-8170 Ihsan DOGAN (D) : 0000-0002-1985-719X Umit EROGLU (D) : 0000-0001-8623-071X
Serhat AKTAN Irem KAR

Gizem CAKICI

(1) : 0000-0002-1375-4026

Eyyub S M AL-BEYATI (D) : 0000-0001-6246-4247
Gokmen KAHILOGULLARI (D) : 0000-0001-8137-0510 Agahan UNLU (D): 0000-0002-2039-8592 
Laboratories. Sixty fertile non-pathogenic Super Nick eggs were obtained from the Institute of Akyurt Poultry Husbandry. All eggs weighed (overall weight $=65 \pm 2 \mathrm{~g}$ ) and incubated for 24 hours (h) at a temperature of $37.8 \pm 2{ }^{\circ} \mathrm{C}$ and $65-75 \%$ humidity in an incubator that rotated the eggs every $2 \mathrm{~h}$ after which the eggs were opened using the window procedure (Figure 1), and were divided into four groups of 15 eggs each. Under sterile conditions, selected dosages (low, normal, and high) of Phe were prepared and $12.5 \mu \mathrm{L}$ was administered through the sub-blastoderm in Groups 2, 3, and 4 at concentrations of 10,60 , and $280 \mathrm{mg} / \mathrm{mL}$, respectively, using a 0.12-, 0.75-, or 3.5-mg Hamilton microinjector (Figure 2). Group 1 served as the control group and $12.5 \mu \mathrm{L}$ distilled water was administered through the sub-blastoderm. The eggs were covered with sterile drapes after injection, rotated $180^{\circ}$, and incubated for another $24 \mathrm{~h}$. All eggs were evaluated morphologically and histopathologically. The eggs were opened using of new method and evaluated under the Nikon ZMS-20 light microscope in terms of neural development. The embryos were classified according to defect, normal or undeveloped criteria.

Analyses of all findings were conducted using SPSS v 17.0 (SPSS Inc., Chicago, IL, USA). The results are expressed as number and percentage. Fischer's Chi-Squared test was performed to determine any differences among the groups.

\section{- RESULTS}

Of the embryos in Group 1, none exhibited NTDs (0\%), 1 $(6.6 \%)$ was undeveloped, and $14(93.3 \%)$ were intact. Of the embryos in Group 2 (low dosages), 1 did not develop (6.6\%) and $14(93.3 \%)$ were intact. Of the embryos in Group 3 (normal dosages), 2 (13.4\%) had NTDs, 1 (6.6\%) was undeveloped, and 12 (80\%) were intact. In Group 4 (high dosages), 5 (33.3\%) had NTDs, 2 (13.3\%) were undeveloped, and 8 (53.4\%) were intact (Figures 3A, B; 4A, B). Drug dosages in the groups are shown in Table I.

There was no significant difference in NTDs between Groups 1 and 2 ( $p>0.05)$. There was a significant difference in NTDs between Groups 1 and $4(p<0.05)$ and between Groups 2 and $4(p<0.05)$. Based on our findings, Phe may cause NTDs and abnormality in early chick embryos in a dose-dependent manner.

\section{DISCUSSION}

Although NTDs are the most common congenital malformation of the central nervous system, the cause has not been clearly determined. It is believed to be multifactorial with the effects stemming from both genetic and environmental factors $(4,12)$. Some environmental factors, such as maternal infections, trauma, folic acid deficiency, and drug use, can affect neural development and cause neural developmental disorders in the early stages of pregnancy $(2,8)$. There have been studies on early chicken embryo models, such as the effects of magnetic resonance imaging and cell phone use during pregnancy $(9,21)$; however, too many studies have been performed with drugs. The drugs studied are antiepilectics, such as valproic acid, levetiracetam, lacosamide; analgesics, such as meloxicam, flurbiprofen, metamizole; folic acid antagonists, such as methotrexate; and myeline protector proteins such as glatiramer $(3,6,7,13,15,16,18,20,22)$. One of the most common features of these studies is that they were conducted on early chicken embryo models. This study timeframes correspond to the first trimester in pregnancy, during which neural development begins (5).

Between $20 \%$ and $90 \%$ of pregnant women worldwide experience low back pain $(11,23,24)$. The etiology is explained as being from a combination of hormonal changes, postural changes, and reduced stability from increasing strains on core
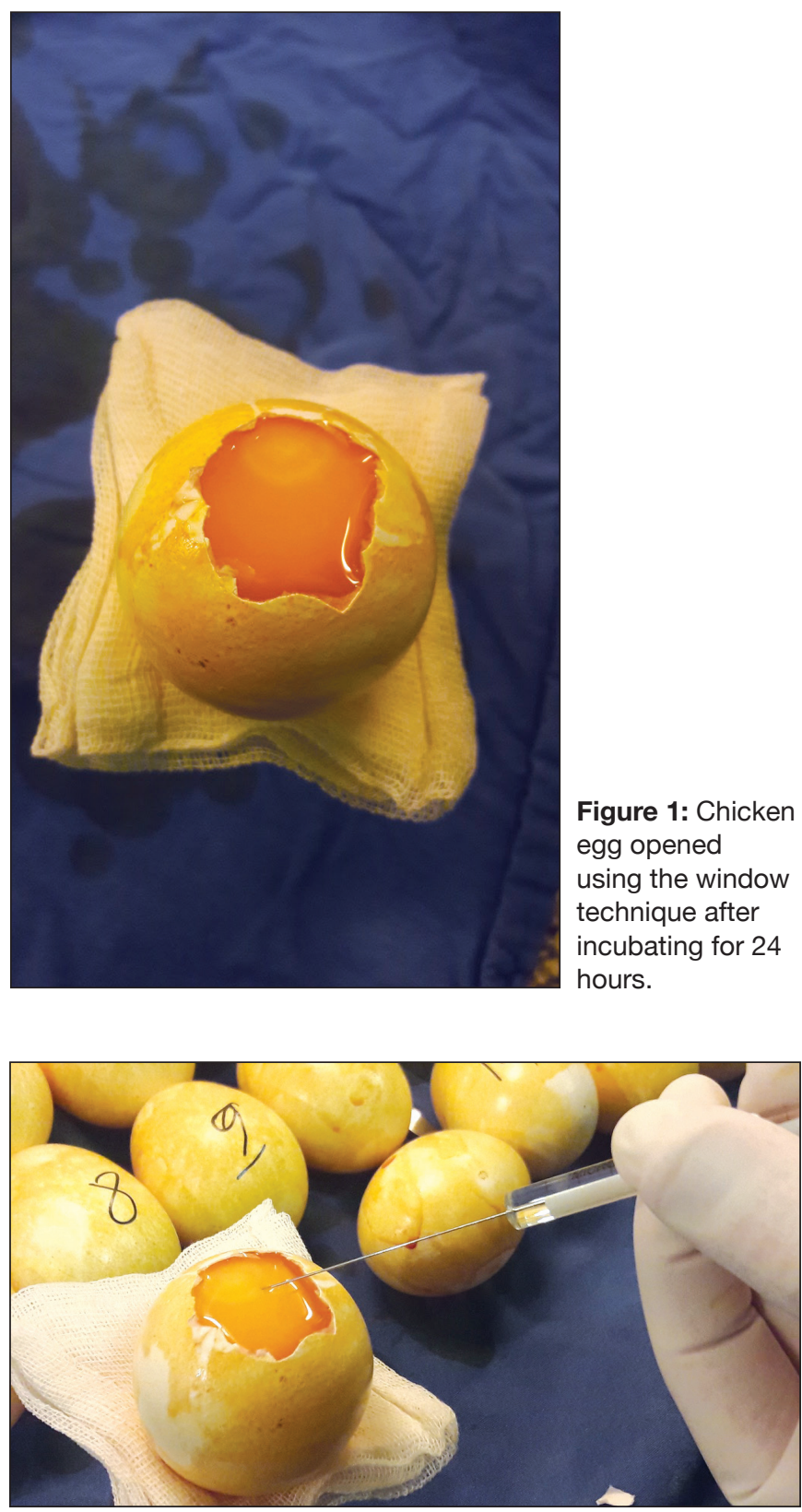

Figure 2: Phenyramidol injected through the sub-blastoderm under sterile conditions. 
muscles, metabolic factors, genetic factors, and increased pregnancy (24). Low back pain results in increased sick leave, higher rates of functional disability, and increased access to healthcare for symptom management (10); therefore, pain elimination or reduction is important for a healthy pregnancy.
Simple analgesics, nonsteroidal anti-inflammatory drugs, opioids, and myorelaxants are used for pain relief. Guvenc et al. found that metamizole sodium, an analgesic, causes NTDs in the chicken embryo model. In another study with 36 chicken embryos (7), Ozeren et al. showed that even the

Table I: Variable Dosages and Effects in Different Groups of Phenyramidol

\begin{tabular}{ccccc}
\hline Groups & $\begin{array}{c}\text { Control } \\
\mathbf{n ~ ( \% )}\end{array}$ & $\begin{array}{c}\text { Low (10 } \mathbf{~ m g} / \mathbf{m l}) \\
\mathbf{n ~ ( \% )}\end{array}$ & $\begin{array}{c}\text { Normal (60mg/ml) } \\
\mathbf{n ~ ( \% )}\end{array}$ & $\begin{array}{c}\text { High (280mg/ml) } \\
\mathbf{n ~ ( \% )}\end{array}$ \\
\hline Undeveloped & $1(6.6)$ & $1(6.6)$ & $1(6.6)$ & $2(13.3)$ \\
\hline NTD & $-(0)$ & $-(0)$ & $2(13.4)$ & $5(33.3)$ \\
\hline Intact & $14(93.3)$ & $14(93.3)$ & $12(80)$ & $8(53.4)$ \\
\hline
\end{tabular}

NTD: Neural tube defect.
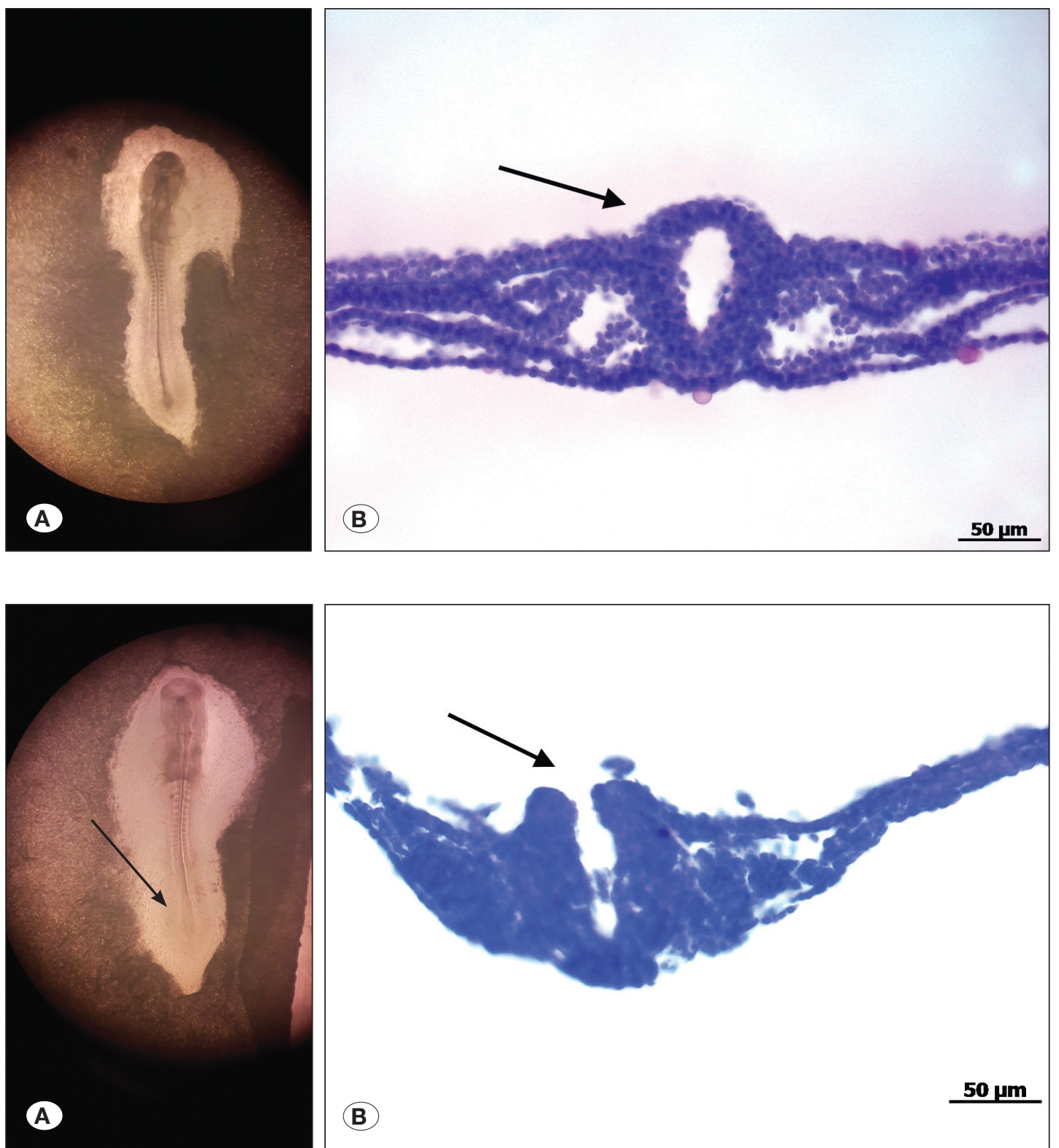

Figure 3: Neural tube of chicken embryo. A) Light microscopic (x40), and B) histopathological (hematoxylin and eosin staining) views.
Figure 4: Neural tube of defect in a chicken embryo (black arrows). A) Light microscopic (x40), and B) histopathological (hematoxylin and eosin staining) views. 
normal therapeutic doses of flurbiprofen increase the risk of NTDs and anencephaly (15). Cetinkal et al. administered various dosages of meloxicam, a COX-2 inhibitor, to 100 nonpathogenic chicken embryos (3). Their results showed NTDs in the embryos after having received supratherapeutic dosages of the drug. All of these studies showed that nonsteroidal antiinflammatory drugs can affect neural development, even at normal dosages.

Briner administered muscimol and bicuculline, which are $\gamma$-aminobutyric acid $(\mathrm{GABA})_{A}$ agonists, and baclofen and hydroxyl-baclofen, which are $\mathrm{GABA}_{\mathrm{B}}$ agonists, to pregnant rats. The results of their research indicated that $\mathrm{GABA}_{A}$ agonist and antagonist and $\mathrm{GABA}_{\mathrm{B}}$ agonist could lead to the enlargement of the vertebral arc and create NTDs (1).

We choose to study Phe because its effects on pregnancy were not studied and were unknown. Phe is an efficacious and well-tolerated analgesic used in the treatment of the acute conditions of lumbago, acute musculoskeletal pain, and integumental pain. It works by interrupting the interneuronal reflexes in the spinal cord and brain stem and has been found to be beneficial for musculoskeletal disorders and integumental pain in both oral and injectable forms (17). The results of our study showed that Phe, especially in increasing dosages, affects neural development to and leads to NTDs.

There are a many steps in neurulation, such as the development of neural plaque by thickening ectoderm, remodeling and bending of neural plaque, closure of the neural cleft, and closure of the caudal eminence, and ionic changes also play important roles in this development (25). We believe that it is not known exactly which step in this process is affected by Phe, but the drug can block ion exchanges and thus lead to defects by creating stress on neural development.

\section{CONCLUSION}

High doses of Phe might have an effect on neural development and cause NTDs in early chicken embryo models; therefore, those in the first trimester of pregnancy should avoid using this drug for pain relief.

This is the first experimental study on Phe involving neural development with an early chicken embryo model. Additional studies are needed to show the mechanisms by which embryos are damaged and the mechanisms surrounding Phe's teratogenous effects that are associated with genetic and environmental factors and to minimize the rate of congenital defects.

\section{ACKNOWLEDGEMENTS}

Preparation for publication of this article is partly supported by Turkish Neurosurgical Society.

\section{- REFERENCES}

1. Briner $W:$ The effect of GABA receptor ligands in experimental spina bifida occulta. BMC Pharmacol 1:2, 2001
2. Bupp Becker SR, Shibley IA Jr: Teratogenicity of ethanol in different chicken strains. Alcohol Alcohol 33:457-464, 1998

3. Cetinkal A, Colak A, Topuz K, Demircan MN, Simsek H, Berber U, Umur AS, Selcuki M, Vatansever HS: The effects of meloxicam on neural tube development in the early stage of chick embryos. Turk Neurosurg 20:111-116, 2010

4. Copp AJ, Berneld M: Etiology and pathogenesis of human neural tube defects: Insights from mouse models. Curr Opin Pediatr 6:624-631, 1994

5. Drake VJ, Koprowski SL, Lough J, Hu N, Smith SM: Gastrulating chick embryo as a model for evaluating teratogenicity: A comparison of three approaches. Birth Defects Res A Clin Mol Teratol 76:66-71, 2006

6. Guney O, Canbilen A, Konak A, Acar O: Effects of folic acid in the prevention of neural tube development defects caused by phenytoin in early chick embryos. Spine 28:442-445, 2003

7. Guvenc Y, Billur D, Aydin S, Ozeren E, Demirci A, Alagoz F, Dalgic A, Belen D: Metamizole sodium induces neural tube defects in a chick embryo model. Turk Neurosurg 26:445-448, 2016

8. Hamburger V, Hamilton HL: A series of normal stages in the development of the chick embryo. Dev Dyn 195:231-272, 1992

9. Kantarcioglu E, Kahilogullari G, Zaimoglu M, Atmis EO, Peker E, Yigman Z, Billur D, Aydin S, Erden IM, Unlü A: The effect of magnetic resonance imaging on neural tube development in an early chicken embryo model. Childs Nerv Syst 34:933-938, 2018

10. Katonis P, Kampourglou A, Aggelopoulos A Kakavelakis K, Lykoudis S, Makrigiannakis A: Pregnancy-related low back pain. Hippokratia 15:205-210, 2011

11. Kovacs FM, Garcia E, Royuela A, Gonzalez L, Abraira V: Prevalence and factors associated with low back and pelvic girdle pain during pregnancy: A multicentre study conducted in the Spanish National Health Service. Spine 37:1516-1533, 2012

12. Manning N, Archer N: Treatment and outcome of serious structural congenital heart disease. Semin Neonatol 6:37-47, 2001

13. Mete M, Gurcu B, Collu F, Unsal UU, Duransoy YK, Tuglu MI, Selcuki M: Effects of lacosamide "a novel antiepi-leptic drug" in the early stages of chicken embryo development. Childs Nerv Syst 32(9):1715-1719, 2016

14. Opitz JM, Wilson GN: Causes and pathogenesis of birth defects. In: Gilbert-Barness EG, (ed), Potter's Pathology of the Fetus and Infant. St. Louis: Mosby, 1997:44-51

15. Ozeren E, Er U, Guvenc Y, Demirci A, Arıkok AT, Senveli E, Ergün RB: The effect of flurbiprofen on the development of anencephaly in early stage chicken embryos. $\mathrm{Br} \mathrm{J}$ Neurosurg 29:265-271, 2015

16. Ozgural O, Armagan E, Bozkurt M, Eroglu U, Kahilogullari G, Unlu A: The effect of levetiracetam on closure of the midline in early chicken embryos. Turk Neurosurg 25:681-684, 2015

17. Shah H, Shakeel A, Karen N, Patil C, Kewalramani R, Kasodekar V, Dave M: Phenyramidol in acute conditions of lumbago, integumental pain and musculo-skeletal pain: An open label, noncomparative, multi-centre study. J Clin Trials 3:27-33, 2011 
18. Taskapilioglu MO, Billur D, Kizil S, Taskapilioglu O, Ocakoglu G, Aydin S, Bekar A, Unlu A: Targeting apoptosis through Foxp1, and $\mathrm{N}$-cadherin with glatiramer acetate in chick embryos during neural tube development. Turk Neurosurg 26:586-594, 2016

19. Tuncbilek E, Boduroglu K, Alikasifoglu M: Neural tube defects in Turkey: Prevalence, distribution and risk factors. Turk J Pediatr 41:299-305, 1999

20. Tureci E, Asan Z, Eser M, Tanriverdi T, Alkan F, Erdincler P: The effects of valproic acid and levetiracetam on chicken embryos. J Clin Neurosci 18:816-820, 2011

21. Umur AS, Yaldiz C, Bursali A, Umur N, Kara B, Barutcuoglu M, Vatansever S, Selcuki D, Selcuki M: Evaluation of the effects of mobile phones on the neural tube development of chick embryos. Turk Neurosurg 23:742-752, 2013
22. Vatansever HS, Umur AŞ, Inan VS, Selcuki M: Effects of methotrexate on the development of neural tube defects in the chick embryo. Turk J Vet Anim Sci 27:1119-1125, 2003

23. Vermani E, Mittal R, Weeks A: Pelvic girdle pain and low back pain in pregnancy: A review. Pain Pract 10:60-71, 2010

24. Verstraete EH, Vanderstraeten G, Parewijck W: Pelvic girdle pain during or after pregnancy: A review of recent evidence and a clinical care path proposal. Obstet Gynecol 5:33-43, 2013

25. Yerby MS: Clinical care of pregnant women with epilepsy: Neural tube defects and folic acid supplementation. Epilepsia 44:33-40, 2003

26. Zhang L, Zhao Y: The regulation of Foxp3 expression in regulatory CD4(+)CD25(+)T cells: Multiple pathways on the road. J Cell Physiol 211:590-597, 2007 